\title{
A apropriação e transformação de As Aves, de Aristófanes, por Paul Muldoon
}

\author{
MUNIRA H. MUTRAN \\ Departamento de Letras Modernas - FFLCH \\ Universidade de São Paulo
}

RESUMO: Um texto como As Aves, de Aristófanes, produzido em Dionísia em 414 a.C., é passivel de diferentes leituras e interpretações. Este artigo examina as relações intertextuais entre o original grego e sua recente tradução pelo poeta irlandês Paul Muldoon; investiga, também, como os motivos predominantes de guerra, política, corrupção e utopia tornaram-se significativos na tradução de 1999.

PALAVRAS-CHAVE: Tradução; apropriação; reescritura; Grécia - Irlanda.

A tendência de traduzir ou adaptar a tragédia grega pelo teatro irlandês contemporâneo tem sido observada por muitos críticos. A reescritura dos clássicos, embora não seja algo novo - W. B. Yeats, John Millington Synge e James Joyce o fizeram nas primeiras décadas do século $\mathrm{XX}$ - tornou-se um meio importante de reflexão sobre o presente na Irlanda.

A recepção e crítica destas peças concentra-se, geralmente, nos processos de tradução ou adaptação, ou na maneira pela qual o texto-fonte foi reelaborado. Um novo ângulo pode ser visto em dois ensaios de Shaun Richards sobre o costume de usar a tragédia grega (direta ou indiretamente) para ilustrar os problemas da Irlanda do Norte (Ulster) nos dias de hoje. Seu principal argumento baseia-se no perigo de se empregar o gênero trágico em relação aos conflitos norte-irlandeses assim causando "a aceitação da inevitabilidade e irrevocabilidade das ações humanas" (Richards, 1995, p. 192). Apoiado em outros críticos e historiadores, como Seamus Deane, Richards enfatiza o risco da crença de que o que acontece na Irlanda do Norte pertence ao âmbito do destino, e conclui que algumas tragédias podem "congelar a Irlanda em um círculo fatal". (1995, p. 197).

Em "Into that Rinsing Glare?", outro ensaio sobre esta questão, Richards cita Deane sobre o uso da tragédia:

... embora tais obras possam despertar no público sentimentos de piedade para com as vítimas de um sistema político, elas não os informam até que 
ponto o sistema político é algo à parte ou distante deles. Eles são seus habitantes; são, também, de várias maneiras, aqueles que o criaram. No entanto, quando os levantes e a violência sectária explodem na Província [Ulster], o termo adotado é 'tragédia' (Richards, 2000, p. 109).

O principal ponto de Deane, como se pode ver na citação acima, é a responsabilidade dos habitantes da região pelos conflitos constantes; a palavra tragédia é inadequada para descrever a situação política que se eterniza, e mais ainda, o gênero trágico é inadequado para ilustrá-la.

Richards insiste que o grande número de tragédias que revelam a imagem do Ulster "como uma casa de Atreu contemporâneo", "uma raça caminhando para sua destruição", não ajuda em nada a solução do conflito.

Ao constatar, porém, o uso de tantas Antígonas, Fedras, Hipólitos e Medéias no fim do século XX e início deste, percebe-se um desejo de mudança de ponto de vista, em pelo menos uma das peças. Refiro-me a The Cure at Troy. A Version of Sophocles' Philoctetes (1990) de Seamus Heaney'. A epígrafe escolhida, de um poema de W. H. Auden, é reveladora:

O look, look in the mirror,

O look in your distress;

Life remains a blessing

Although you cannot bless.

O stand, stand at the window

As the tears scald and start;

You shall love your crooked neighbour

With your crooked heart ${ }^{2}$.

As analogias entre a ilha de Lemnos e a ilha da Irlanda são muitas vezes realçadas; as diferenças são mais importantes, talvez. De acordo com Eugene O'Brien, na reescritura da peça de Sófocles, Heaney "tenta transcender o binarismo de nacionalistas e unionistas" (2002, p. 110). A cura, do título, e a epígrafe citada indicam um desvio na transposição: Filoctetes poderá permitir que a auto-compaixão, o ressentimento e o ódio arrefeçam e sejam substituídos pela compreensão e por uma espécie de "confiança aleijada". O "vou odiar este homem para sempre" pode, por um milagre, transformar-se na meia-esperança do coro que afirma que "a quase verdadeira rima é o amor" (Heaney, 1990, p. 81). Filoctetes concorda em voltar à Tróia, não devido a uma intervenção sobrenatural, mas como resulta-

1 Seamus Heaney (1939) poeta irlandês, nasceu em County Derry, Irlanda do Norte. Autor de volumes de poesia como Door into the Dark (1969), North (1975), Station Island (1984), The Spirit Level (1996) e outros. Recebeu o Prêmio Nobel de Literatura em 1995.

2 Tradução literal: Olha, olha no espelho/ Olha para teu desespero/ A vida é ainda uma bênção/ Embora você não possa abençoar os outros./ Fica, fica junto à janela/ Enquanto as lágrimas queimam os olhos e transbordam/ Amarás teu próximo cruel/ com teu cruel coração. 
do das discussões com Neoptólemo e sua admiração pelos valores éticos do jovem. E o coro alegra-se (Heaney, 1990, p. 77) ${ }^{3}$ :

\section{So hope for a great sea-change}

On the far side of revenge.

Believe that a further shore

Is reachable from here.

Haverá, portanto, a possibilidade de uma reconciliação política? Ao usar a peça de Sófocles, Heaney ao mesmo tempo distancia-se e se aproxima do contexto irlandês dando muito peso à responsabilidade humana.

Como se também quisesse livrar-se do círculo fatal da tragédia, Paul Muldoon ${ }^{4}$, diferentemente de outros dramaturgos seus contemporâneos, elege uma comédia de Aristófanes para conseguir um efeito de distanciamento dos problemas do presente. The Birds (1999) é uma tradução bastante próxima de As Aves em termos de enredo e estrutura, personagens e conteúdo. Se for comparada, como o fiz, com duas traduções acadêmicas, uma relativa semelhança com o texto-fonte pode ser observada. Evidentemente, a peça de Aristófanes (414 a.C.) passa por ajustes em sua adaptação para um público de 1999. Como sabemos, e Maria Tymocsko não deixa de nos lembrar, "a teoria da tradução demonstrou que a reescritura não consiste de um processo inocente ou objetivo; envolve manipulação e o exercício do poder" (Tymocsko, 2003, p. 193). Em As Aves, Tereu, personagem do mito de Procne e Filomela, encontrado em Hesíodo, em Homero, na tragédia Tereu, de Sófocles e nas Metamorfoses, de Ovídio, é agora uma ave, o ponto de partida para a comédia de Aristófanes. Chamada por Alan H. Sommerstein de "fantasia do poder total", relata a chegada de dois cidadãos à terra dos pássaros, cansados que estão da vida em Atenas com seus políticos corruptos, magistrados inescrupulosos, e com a futilidade das classes dominantes. Descaradamente usam a lisonja num "discurso gordo e imenso" (Muldoon, 69) cheio de mentiras, para convencer as ingênuas aves a construir uma cidade nas nuvens, "linda e agradável, macia como um manto de lã" (Aristophanes, 1991, p. 29). As aves governarão a cidade, os homens e os deuses, que, se não quiserem pagar impostos para o novo Estado, morrerão de fome pois os sacrifícios passarão pela cidade construídas nas nuvens apenas com o seu consentimento. Zeus decide enviar Embaixadores em busca de um tratado de paz. Quando Héracles, Posêidon e Tribalo (o novo deus dos Bárbaros) chegam, Pistétero acabou de matar alguns pássaros para um churrasco. Héracles, violento e também glutão, primeiro quer esganar todo mundo mas logo se deixa convencer com todas as palavras do tratado se puder participar da deliciosa refeição. Tribalo, incapaz de entender uma única palavra da discussão, e com medo da truculência de Héracles, tudo aceita. Pistétero consegue casar-se com

3 Tem esperança numa mudança imensa como o mar/ Do outro lado da vingança./ Acredita que uma outra praia pode ser alcançada a partir daqui.

4 Paul Muldoon (1951) poeta da Irlanda do Norte, autor de, entre outros, New Weather (1973), Mules (1977), Quoof (1983) e organizador do Faber Book of Contemporary Irish Poetry (1986). 
uma deusa e o coro comemora seu triunfo como o "mais alto dos deuses" (Aristophanes, 1991, p. 199).

Qual o significado desta fantasia ou sátira? Como sabemos, Aristófanes consideravase um educador e como tal, escreveu comédias para fazer rir e ao mesmo tempo, despertar a consciência ética do público. O uso da sátira, da ironia e do humor leva ao riso mas também perturba. Talvez por pouco tempo? E esta poderia ser a maior ironia da comédia? Como lembra Adriane da Silva Duarte, na introdução à As Aves:

Não cabia à comédia apresentar soluções embora, às vezes, o poeta se autointitulasse conselheiro. A poeira que ela levantava era assentada de imediato pelo riso desopilador. [...] O riso exorciza os males e alivia as tensões, permitindo que a vida retome seu curso (As Aves, 2000, p. 12).

Isso não quer dizer que a crítica à sociedade ateniense como um todo, e não apenas em seus aspectos políticos, não seja capaz de deixar bem claro o contrário do que é desejável. Mostra que homens, deuses e aves são igualmente cheios de defeitos. Prometeu, por exemplo, o arqui-rebelde, aparece como um ridículo mexeriqueiro cujo único objetivo é semear a discórdia entre os homens e os deuses. As aves, apesar de trabalhadoras, são ambiciosas e ingênuas, acreditando facilmente nas mentiras de homens que, como Pistétero, têm grande poder de persuasão e sabem despertar seus sentimentos de vaidade. A grande ironia da peça revela o fato de que a aparentemente utópica cidade nas nuvens é, na verdade, outra Atenas: ali também prevalecem a corrupção, crueldade, tortura e injustiça. Como não lembrar Animal Farm, de George Orwell (1945), em que a utopia se transforma em distopia quando os porcos, fascinados pelo poder, tornam-se mais cruéis que os homens, contra os quais os bichos haviam feito a revolução?

A ênfase da tradução de Muldoon recai no conteúdo, sendo relativamente fiel na estrutura do enredo, na caracterização, no tom e na atitude da comédia de Aristófanes. $O$ tradutor mantém, por exemplo, a leveza do diálogo, o uso da gíria, de piadas e imprecações, de linguagem chula, descrições indecentes, de trocadilhos; mantém ainda a musicalidade da fala das aves; o humor e a ironia, e as referências, nem sempre lisonjeiras, a Sócrates, Esopo, Homero e aos dramas de Sófocles e Ésquilo.

Pode-se, então, perguntar como o diálogo intertextual representa tanto os problemas da sociedade antiga como da contemporânea. O principal recurso é colocar palavras, sentenças, expressões e situações aqui e ali (e sempre de acordo com o texto-fonte) que são referências e alusões facilmente reconhecidas pelo público. Na produção de Filoctetes, de Heaney, um dos recursos foi usar o sotaque da Irlanda do Norte falado pelos unionistas e com isso, assegurou-se que as analogias seriam feitas entre os dois universos.

Em The Birds, Muldoon, ao chamar a nova cidade de Nebulbulfast determina, já no início, o local onde se passa a ação de As Aves, e as pessoas presentes pensarão: "Ah, então esta história poderia estar ocorrendo em Belfast!”. Além desse, outros desvios, embora pequenos, ocorrem. Por exemplo, a recorrência das palavras "paz" e "tratado". Mas a paz não é fácil de alcançar em Nebulbulfast. Tão logo a cidade "ideal" fica pronta, irrompe a guerra entre homens e deuses, deuses e aves, homens e aves. Palavras muito usadas nas 
manchetes, na T.V., no rádio e nas conversas do dia a dia norte-irlandês, aparecem: "luta armada", "cessar fogo", "agitação civil", "bombardear totalmente o palácio", "violar o espaço aéreo", "discutir os termos do tratado", "agitação civil", "violação da segurança", "som do helicóptero" (este som, no original, é produzido pelo ataque de trinta mil pássaros).

$\mathrm{Na}$ tradução de Muldoon todas as personagens de Aristófanes estão presentes, incluindo o coro das vinte e quatro aves; mas alguns nomes são alterados. Assim, o jovem que acredita na liberdade total até para "estrangular e apunhalar seu pai e roubar seu pé-demeia" (Muldoon, 1999, p. 63) é um "birdnik" (referência a "beatnik"); o vendedor de decretos é o "ombirdsman"; o delator, Dedo Duro.

As analogias mais evidentes têm relação com Belfast, a capital da Irlanda do Norte. No entanto, os motivos da guerra, corrupção, egoísmo, ambição e, acima de tudo, a violência, não pertencem apenas às fronteiras do Ulster mas podem ser aplicados a qualquer lugar, em qualquer época. Tanto que o "ombirdsman" afirma que "é um observador independente da comunidade internacional, designado pelo Alto Comissário da UN (União de Nebulbulfasts)" (Muldoon, 1999, p. 50). Isto quer dizer que muitas cidades como a das aves existem. Cidades violentas, em que o conflito pelo poder é acirrado pelos interesses pessoais dos diferentes grupos étnicos ou religiosos ou políticos. Por exemplo, as inocentes (mas tolas) aves que tanto se esforçaram para construir o sonho nas nuvens, são bem recompensadas:

Héracles: O que você está cozinhando?

Pistétero: Na verdade, passarinhos.Muitos foram julgados e condenados à morte por traição. Rebeldes. Estavam contra a Liga Aviária (Muldoon, 1999, p. 73).

A violência não se limita às aves. Quando a deusa Iris viola o espaço aéreo, é interrogada, sexualmente molestada e mentalmente torturada; e enfim, Pistétero a ameaça:

Pistétero: Você se encontra em uma situação extremamente comprometedora. Pode ser condenada à morte.

Iris: Morte? Sou positivamente imortal!

Pistétero E daí? Vai morrer assim mesmo. Você compreende que não podemos permitir este tipo de conduta.

Em vez de nos fazer sentir terror e piedade, como na tragédia, esta comédia expõe o comportamento dos deuses, heróis, homens e aves e nos causa o riso. Não é seu destino agir desta maneira, não estão "congelados no círculo fatal" - a natureza humana deve ser culpada pelos vícios de tal sociedade. A idéia principal, para Muldoon, retirada de Aristófanes, é que somos livres e responsáveis para agir e, portanto, capazes de mudar as coisas.

Em As Aves Aristófanes abre nossos olhos para o perigo da habilidade lingüística. Segundo Adriane da Silva Duarte este é o principal tema da peça:.

A palavra de Bom de Lábia é poderosa não só porque é capaz de alterar o mundo, mas também porque confere poder ao seu usuário. De um velho 
exilado, fragilizado no começo da peça, ele se torna no final no senhor dos pássaros, dos deuses e dos homens. Seu casamento com Soberania colocao acima do próprio Zeus, transformando-o em mestre do universo. (Duarte, 2000, p. 15)

Paul Muldoon, em sua tradução, não deixa de lado o aspecto altamente perigoso do discurso de certos líderes. (Na Irlanda são muitos...). Para ele, entretanto, o principal interesse que o texto-fonte tem para seu contexto está em mostrar que uma situação de conflito é resultado das falhas da natureza humana e não da vontade dos deuses. Ao satirizar Nebulbufast Muldoon revela postura relativamente otimista quanto à possibilidade de solução para a Irlanda do Norte.

\section{Referências Bibliográficas}

ARISTOPHANES. Birds. Translation by Alan H. Sommerstein. Wiltshire, England: Aris and Philips, 1991.

ARISTÓFANES. As Aves. Tradução de Adriane da Silva Duarte. São Paulo: HUCITEC, 2000. . As Aves. Tradução de Antonio Medina Rodrigues. São Paulo: Editora 34, 2001.

HEANEY, Seamus. The Cure at Troy. A Version of Sophocles' Philoctetes. London: Faber and Faber in association with Field Day, 1990.

Mc DONALD, Marianne and J. Michael Walton. Amid Our Troubles. Irish Versions of Greek Tragedy. London: Methuen, 2002.

Muldoon, Paul. The Birds. Translated from Aristophanes by Paul Muldoon with Richard Martin. Loughcrew, Ireland: The Gallery Press, 1999.

Murray, Christopher. "Three Irish Antigones". In Perspectives of Irish Drama and Theatre. ed. Jacqueline Genet and Richard Allen Cave. Savage, Maryland: Barnes and Noble, 1991.

O'Brien, Eugene. Seamus Heaney. Creating Irelands of the Mind. Dublin: The Liffey Press, 2002.

OVIDE. Les Métamorphoses. Paris: Éditions Garnier Frères, 1953.

RICHARDS, Shaun. "In the Border Country: Greek Tragedy and Contemporary Irish Drama". In Ritual Remembering. Amsterdam: Rodopi, 1995.

"Into that Rinsing Glare?: Field Day's Irish Tragedies". Modern Drama, Volume XLIII, Number 1, Spring 2000.

TYMOCZKO, Maria. "Cultural Translation in Twentieth-Century Irish Literature" In Kaleidoscopic Views of Ireland. ed. Munira H. Mutran and Laura Z. Izarra. São Paulo: Humanitas, 2003. 
MUTRAN, Munira H. "Paul Muldoon's appropriation and transformation of Birds, by Aritophanes”. Classica, São Paulo, v. 15/16, n. 15/16, p. 269-275, 2002/2003.

ABSTRACT: A text like Birds, by Aristophanes, produced at City Dyonisia in 414 B.C., is open to many different readings and interpretations. This article examines the intertextual relations between the ancient source and its recent translation by Paul Muldoon; it also investigates how the predominant motifs of politics, war, corruption, and utopia become very significant in the 1999 translation.

KEYWORDS: Translation; appropriation; rewriting; Greece-Ireland. 